\title{
R\&D ERL: Photocathode Deposition and Transport System
}

D. Pate, I. Ben-Zvi, T. Rao, A. Burrill, R. Todd, J. Smedley (BNL)

D. Holmes (AES, Medford, NY)

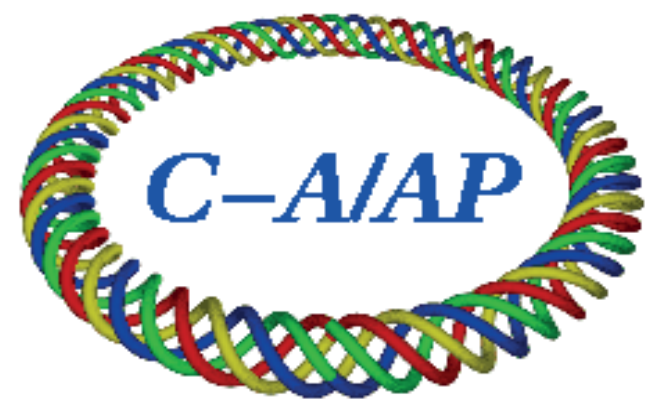

\section{Collider-Accelerator Department Brookhaven National Laboratory \\ Upton, NY 11973}

Notice: This document has been authorized by employees of Brookhaven Science Associates, LLCunder Contract No. DE-AC02-98CH10886 with the U.S. Departm ent of En ergy. The United States Governm ent retains a nonexclusive, paid-up, irrevocable, world-wide license topublish or reproduce the published formof this document, or allow others to do so, for United States Government purposes. 


\section{ERL R\&D - PHOTOCATHODE DEPOSITION AND TRANSPORT SYSTEM}

David Pate ${ }^{\#}$, Ilan Ben-Zvi, Triveni Rao, Andrew Burrill, Rob Todd, John Smedley, Brookhaven National Laboratory, Upton, NY 11973

Doug Holmes, Advanced Energy Systems, Medford, NY 11763

\section{INTRODUCTION}

The purpose of the photocathode deposition and transport system is to (1) produce a robust, high yield multialkali photocathode and (2) have a method of transporting the multialkali photocathode for insertion into a super conducting RF electron gun. This process is only successful if a sufficient quantum efficiency lifetime of the cathode, which is inserted in the SRF electron gun, is maintained. One important element in producing a multialkali photocathode is the strict vacuum requirements of $10^{-11}$ torr to assure success in the production of longlived photocathodes that will not have their QE or lifetime depleted due to residual gas poisoning in a poor vacuum. A cutaway view of our third generation deposition system is shown in figure 1.

There are certain design criteria and principles required. [1] One must be able to install, remove, rejuvenate and replace a cathode without exposing the source or cathode to atmosphere. The system must allow one to deposit $\mathrm{Cs}, \mathrm{K}$, and $\mathrm{Sb}$ on a cathode tip surface at pressures in the $10^{-10}$ to $10^{-9}$ torr range. The cathode needs to be heated too as high as $850^{\circ} \mathrm{C}$ for cleaning and maintained at $130^{\circ} \mathrm{C}$ to $150^{\circ} \mathrm{C}$ during deposition. There should also be the capability for in-situ QE measurements. In addition the | preparation of dispenser -photocathodes [2] must be accounted for, thus requiring an ion source for cathode cleaning. Finally the transport cart must be mobile and be able to negotiate the ERL facility labyrinth.

\section{PHOTOCATHODE DEPOSITION SYSTEM}

In describing the photocathode deposition system; [1] it has deposition sources for $\mathrm{Cs}, \mathrm{K}$ and $\mathrm{Sb}$, it is all metal construction including gate valves-all bakeable to $250^{\circ} \mathrm{C}$, it has adequate pumping $(250 \mathrm{l} / \mathrm{s}$ ion pump with 2 NEG's) with a measured base pressure of $2 \times 10^{-10}$ torr or better after bakeout. It has a radiant heater for cathode tip cleaning, a quartz crystal balance for measuring the deposition rate from the

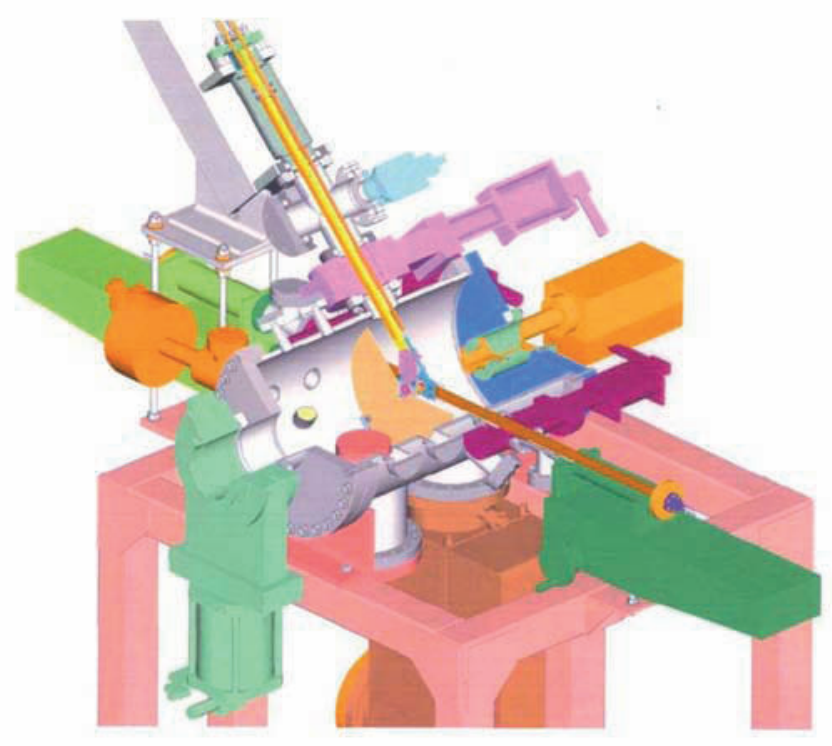

Figure 1. A cutaway view of the third generation multi-alkali deposition system.

three sources and a laser port and collector for QE measurements. 


\section{TRANSPORT CART}

The transport cart shown in figure 2; [1] has two vacuum crosses separated by a long stroke bellows, has adequate pumping (200 1/s ion pump on the front cross, $40 \mathrm{l} / \mathrm{s}$ ion pump on the rear cross with additional NEG's) with an expected base pressure of $10^{-10}$ torr or better after bakeout. It is all metal construction including valves-all bakeable to $250^{\circ} \mathrm{C}$. Additionally there are two transport carts that have been fabricated thus allowing for quick turn around when changing a cathode out of the injector, or while carrying out photocathode R\&D while the ERL is operational.

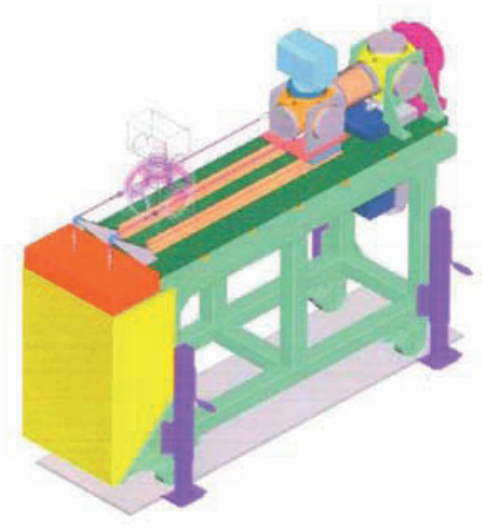

Figure 2. A view of the transport cart.

\section{HISTORY}

Multialkali photocathode development at BNL has gone through a number of generations as we learn more about the challenges of making a robust viable cathode. The challenge of obtaining sufficient vacuum, the importance of high temperature bakeout $\left(450^{\circ} \mathrm{C}\right.$ for main vacuum components) and the choice of sources have all been key in developing the latest deposition system. Once we felt we could produce a viable multialkali photocathode a transport system had to be developed to allow us to insert the cathode into our injector and deal with the challenges associated with that process.

\section{First Generation}

The first generation system shown in figure3.had some positive results; [3] QE at various wavelengths were measured, uniform emission over 1 " diameter cathodes was demonstrated, favorable lifetime measurements, and favorable high current density measurements were also obtained.[4] The deposition system consisted of three ultra high vacuum chambers, deposition, storage and testing chambers in series, separated from each other by gate valves. The deposition chamber contained four $3 \mathrm{cc}$ molybdenum crucibles that could be heated up to $800^{\circ} \mathrm{C}$. The substrate was held at the end of a linear translator that could move between the deposition, storage and test chambers. The lessons learned in the first generation system were; [3] the system was too large and cumbersome for our needs, the packed powder samples could not be heated quick enough, the time between deposition of different materials was too long and there was the concern of cross contamination of sources.

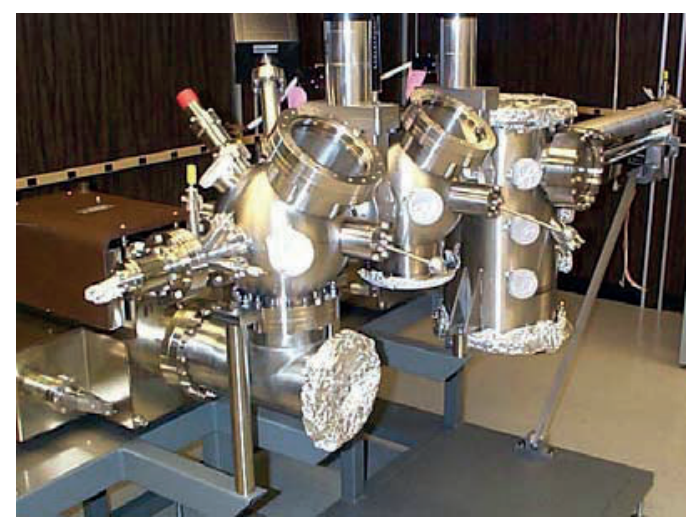

Figure 3. A photograph of the first generation deposition system. 


\section{Second Generation}

The second generation system; [3] used a smaller chamber, less material, had a lower out gassing rate and better vacuum. There is a shorter sourcesubstrate distance with isolated getter sources, which are quick to heat allowing fast photocathode preparation. The sources are pre-made commercially available sources from SAES getter. The system allowed for co-deposition of cathode materials, better photocathodes and deposition on metal or transparent substrate. The second generation system is yielding very positive results but does not address the transportation of the cathode to the SRF Gun. A photograph of the second generation deposition system is shown in figure 4 .

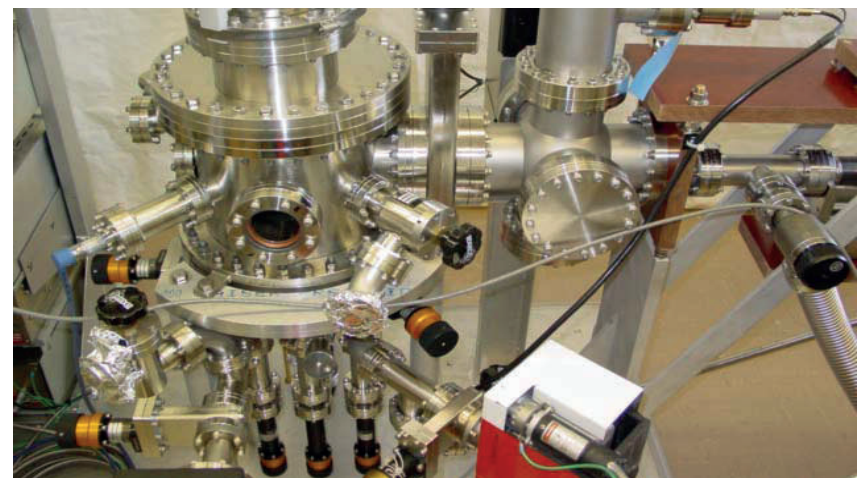

Figure 4. A photograph of the second generation deposition system.

\section{Third Generation}

The third generation multialkali photocathode deposition system built by Advanced Energy Systems (AES) [4] uses similar source technology to the second generation system. The deposition process in this system occurs horizontally on fixed arms, a change from the past two systems. This system has been designed to address the interface to the $703.75 \mathrm{MHz}$ SRF Gun using the aforementioned transporter cart. A photograph of the third generation deposition and transport system is shown in figure 5 .

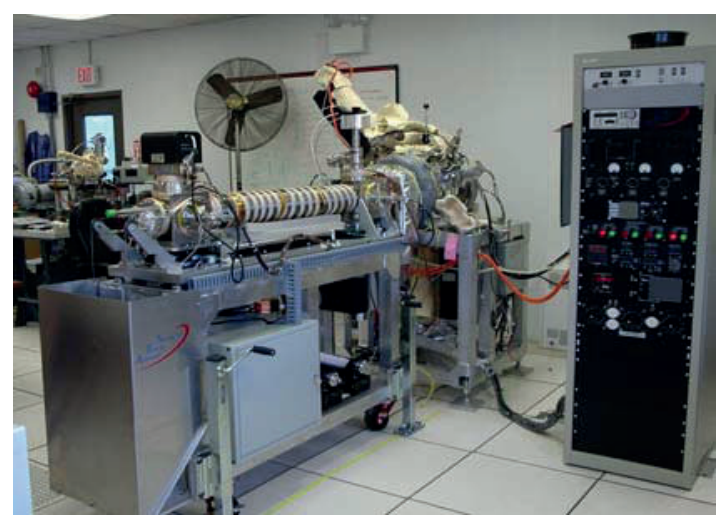

Figure 5. A photograph of the third generation deposition and transport cart system.

\section{PROJECT STATUS}

The Cathode deposition system designed and built by Advanced Energy Systems (AES) was delivered to BNL. All systems have been tested and modified where necessary. A small leak was identified in one of the source isolation valves, which has since been sorted out. There was the need to repair the isolation valves and to redesign the $\mathrm{K}$ and CS source arms to provide a more robust working platform for the deposition process. The deposition system without source material has been bakedout to $200^{\circ} \mathrm{C}$ and leak checked. The system base pressure is $3.2 \times 10^{-10}$ torr with a RGA scan showing the typical high peak of hydrogen. The deposition system will have sources installed and a bakeout of $250^{\circ} \mathrm{C}$ to try and reach a base pressure of $10^{-11}$ torr. It should be noted that this system has not yet received a $450^{\circ} \mathrm{C}$ bake to improve the outgassing of the stainless steel, so this is still an option to further improve the base pressure. 
A recipe for producing photocathodes needs to be developed for this new system. Because similar technology to the second generation deposition system was used by AES, we will use this as a starting point.

The transport carts designed and built by Advanced Energy Systems (AES) were delivered to BNL. As stated early, one important element in producing a multialkali photocathode is the strict vacuum requirements of $10^{-11}$ torr. One of the main elements that cause a photocathode to degrade is the deposition of residual gases on the surface. Having been unable to obtain the desired base pressure in the transport carts a rework and redesign was required. The cleaning, high temperature vacuum baking $\left(450^{\circ} \mathrm{C}\right.$ for main vacuum components), proposed addition of a NEG and other redesigns are being implemented.

The production of cathodes in the third generation deposition system requires the transport cart. It is the transport cart that houses the cathode and allows the cathode to be inserted into the deposition system. We look forward to producing a cathode and testing the deposition system when a transport cart becomes available.

\section{References}

[1] D. Holmes et.al.; "Cathode Deposition and Transport Systems", Advanced Energy Systems, Inc.

[2] E.J. Montgomery et.al.; "Advances in Cesium Dispenser Photocathodes; Modeling and Experiment", J. Directed Energy, 3, 66-79 (2008).

[3] A. Burrill et.al. ; "Multi-alkali photocathode development at BNL for applications in superconducting photoinjectors", Proceedings of 2005 PAC, Knoxville, TN.

[4] A Burrill, "Cathode Deposition System", Brookhaven National Lab, CAD Electron Cooling Website

\#dpate@bnl.gov 